\title{
The effects of size and period of administration of gold nanoparticles on rheological parameters of blood plasma of rats over a wide range of shear rates: In vivo
}

\author{
Mohamed Anwar K Abdelhalim
}

\begin{abstract}
Background: Blood viscosity appears to be independent predictor of stroke, carotid intima-media thickening, atherosclerosis and most cardiovascular diseases. In an attempt to understand the toxicity and the potential threat of GNPs therapeutic and diagnostic use, an array of rheological parameters were performed to quantify the blood plasma response to different sizes and administration periods of GNPs over a wide range of shear rates.

Methods: Healthy, thirty male Wistar-Kyoto rats, 8-12 weeks old (approximately $250 \mathrm{~g}$ body weight) were divided into control group ( $N G$ : $n=10$ ), group 1 (G1A: intraperitoneal infusion of $10 \mathrm{~nm}$ GNPs for 3 days, $n=5$ and G1B: intraperitoneal infusion of $10 \mathrm{~nm}$ GNPs for 7 days, $n=5$ ), group 2 (G2A: intraperitoneal infusion of $50 \mathrm{~nm}$ GNPs for 3 days, $n=5$ and G2B: intraperitoneal infusion of $50 \mathrm{~nm}$ GNPs for 7 days, $n=5$ ). Dose of $100 \mu \mathrm{l}$ of GNPs was administered to the animals via intraperitoneal injection. Blood samples of nearly $1 \mathrm{ml}$ were obtained from each rat. Various rheological parameters such as torque, shear stress, shear rate, viscosity, plastic velocity, yield stress, consistency index $(k)$ and flow index $(n)$ were measured in the blood plasma of rats after the intraperitoneal administration of 10 and $50 \mathrm{~nm}$ GNP for 3 and 7 days using Brookfield LVDV-III Programmable rheometer.

Results: The relationship between shear stress and shear rate for control, G1A, G1B, G2A and G2B was linearly related. The plastic viscosity and the yield stress values for G1A, G1B, G2A and G2B significantly $(p<0.05)$ decreased compared with the control. The $n$ and $k$ values calculated from equation (1). The $k$ values for G1A, G1B and $\mathrm{G} 2 \mathrm{~B}$ decreased compared with the control; however the means were not significantly different. While G2A indicates no significant change compared with the control. The values of the flow behaviour index $(n)$ were equal $\leq 1$ for all the different GNPs sizes. The viscosity values measured for 10 and $50 \mathrm{~nm}$ GNPs (G1A, G1B, G2A and G2B) decreased compared with the control; however the means were not significantly different. The decrease in blood plasma viscosity values observed with all GNPs is particle size and administration period independent.
\end{abstract}

Conclusions: At these particular shear rates, the estimated rheological parameters are not influenced by GNPs size and shape, number of NPs, surface area and administration period of GNPs. This study demonstrates that the highly decrease in blood plasma viscosity was accompanied with the smaller $10 \mathrm{~nm}$ GNPs compared with the 50 nm GNPs. The decrease in blood plasma viscosity induced with 10 and $50 \mathrm{~nm}$ GNPs may be attributed to decrease in hematocrit and haemoglobin concentration in addition to erythrocyte deformability. This study suggests that histomorphologcal, histochemical and ultrastrucural investigations are needed to evaluate the inflammations and tissue injuries, in relation to the application of GNPs as a therapeutic and diagnostic tool.

Keywords: Gold nanoparticle, sizes, blood plasma, periods, rheological parameters, rats 


\section{Introduction}

The elevation of whole-blood viscosity is a predictor of stroke, carotid intima-media thickening, and atherosclerosis. However, in most studies, whole blood viscosity was measured at a few non-specific shear rates and these data not reflect the complete rheological characteristics in these studies [1-3].

Erythrocytes change their shape extensively under the influence of applied forces in fluid flow or while passing through microcirculation. The extent and geometry of this shape change is determined by both the rheological properties of erythrocytes, the magnitude of the applied forces and the orientation of erythrocytes with the applied forces [1].

Blood viscosity is determined by plasma viscosity, hematocrit and rheological behavior of red blood cells. Therefore, red blood cell mechanics is the major determinant of flow properties of blood. Red blood cells have unique rheological behavior, which can be discussed under the terms erythrocyte deformability and erythrocyte aggregation [2]

Whole-blood Blood is a unique fluid, it exhibits nonNewtonian characteristics, and its viscosity is dependent on shear rate. Major determinants of whole-blood viscosity are haematocrit, plasma viscosity, and red cell aggregation and red cell deformation under conditions of low and high shear rates [4-6].

Plasma fibrinogen concentration and plasma viscosity are elevated in unstable angina pectoris and stroke and their higher values are associated with higher rate of major adverse clinical events. Elevation of plasma viscosity correlates to the progression of coronary and peripheral artery diseases. Plasma viscosity should be measured routinely in medical practice [7].

A study on nanoparticle is becoming a hot point owing to their novel physical and chemical attributes in biology and medicine [8-15].

Owing to the unique optoelectronic properties with their controlled size and morphology [8], GNPs find significance in the field of bionanotechnology [8] as biomarkers [11], cancer diagnostic [8,15], as photo-thermal agents in hyperthermia [14], gene expression [12], and DNA detection [10].

The size of GNPs is similar to that of most biological molecules; therefore, GNPs can be useful for both in vivo and in vitro biomedical research and applications. Thus, an increased attention is focused on the applications of nanoparticles in biology and medicine.

The effect of storage time and temperature on the quality of GNPs as pharmaceutical products can be investigated via rheological measurements. Rheological analysis can be employed as a sensitive tool in predicting the physical properties of the different GNP sizes [16].
The objective of this study was to quantify array of rheological parameters for the blood plasma of rats to different sizes and periods administration of GNPs over a wide range of shear rates.

\section{Materials and methods \\ Gold nanoparticles size}

10 and $50 \mathrm{~nm}$ GNPs were purchased (Product MKN-Au, Canada) and used in this study. The $10 \mathrm{~nm}$ GNPs were dissolved in aqueous solution (Product MKN-Au-010; concentration $0.01 \% \mathrm{Au}$ ) and $50 \mathrm{~nm}$ GNPs (Product MKN-Au-050; concentration 0.01\% Au).

\section{Animals}

Healthy, male Wistar-Kyoto rats were obtained from the Laboratory Animal Centre (College of Pharmacy, King Saud University). 8-12 weeks old (approximately $250 \mathrm{~g}$ body weight) were housed in pairs in humidity and temperature-controlled ventilated cages on a $12 \mathrm{~h}$ day/night cycle. A rodent diet and water were provided. In this study, thirty rats were individually caged, and divided into control group (NG: $\mathrm{n}=10$ ), group 1 (G1A: infusion of $10 \mathrm{~nm}$ GNPs for 3 days, $\mathrm{n}=5$ and G1B: infusion of $10 \mathrm{~nm}$ GNPs for 7 days, $\mathrm{n}=5$ ), group 2 (G2A: infusion of $50 \mathrm{~nm}$ GNPs for 3 days, $\mathrm{n}=5$ and G2B: infusion of $50 \mathrm{~nm}$ GNPs for 7 days, $\mathrm{n}=5$ ). Dose of $100 \mu \mathrm{l}$ of 10 and $50 \mathrm{~nm}$ GNPs dissolved in aqueous solutions were intraperitonealy administered daily to the animals for periods of 3 and 7 days. The rats were anesthetized by inhalation of $5 \%$ isoflurane until muscular tonus relaxed. Blood samples of nearly $1 \mathrm{ml}$ were obtained from each rat. $1 \mathrm{ml}$ of Blood was collected into polypropylene tubes viz., the blood for plasma was collected in EDTA. All experiments were conducted in accordance with the guidelines approved by King Saud University Local Animal Care and Use Committee.

\section{Experimental set up and rheological parameters measurement}

Several rheological parameters for the blood plasma of rats after the administration of 10 and $50 \mathrm{~nm}$ GNPs for periods of 3 and 7 days were measured. The rheological parameters were viscosity, torque, shear stress, shear rate, plastic viscosity, yield stress, consistency index and flow index. These rheological parameters were measured using Brookfield LVDV-III Programmable rheometer (cone-plate viscometer; Brookfield Engineering Laboratory, Incorporation, Middleboro, USA) supplied with temperature bath controlled by a computer. The rheometer was guaranteed to be accurate within $\pm 1 \%$ of the full scale range of the spindle/speed combination in use reproducibility is within $\pm .2 \%$.

Rheological parameters were measured at temperature of $37^{\circ} \mathrm{C}$. Temperature inside the sample chamber was 
carefully monitored using a temperature sensor during the rheological parameters measurement.

A cone and plate sensor having a diameter of $2.4 \mathrm{~cm}$ with an angle of 0.8 was used. The rheometer was calibrated using the standard fluids. This viscometer has a viscosity measurement range of 1.5-30,000 mPas.

The spindle type (SC-40) and its speed combinations will produce results with high accuracy when the applied torque is in the range of $10 \%$ to $100 \%$ and accordingly the spindle is chosen.

$0.5 \mathrm{ml}$ of each GNP size dissolved in aqueous solution was poured in the sample chamber of the rheometer. The spindle was immersed and rotated in these gold nanofluids in the speed range from 20 to 180 RPM in steps of 20 minutes. The viscous drag of the GNP aqueous solution against the spindle was measured by the deflection of the calibrated spring.

\section{Plastic viscosity and yield stress}

The flow curves were plotted between shear stress (dyne $/ \mathrm{cm}^{2}$ ) and shear rate $\left(\mathrm{s}^{-1}\right)$ for each GNP size. Plastic viscosity and yield stress were calculated from the linear fitting of the flow curves $[16,17]$.

\section{Consistency index (k) and flow index (n)}

The consistency index and flow index for the 10 and 50 nm GNPs in aqueous solution can be evaluated by power law model [17]:

$$
\tau=k v^{n}
$$

Where $\tau$ is the shear stress, $\mathrm{k}$ is the consistency index, $v$ is the shear rate, and $\mathrm{n}$ is the flow behaviour index [17].

\section{Statistical analysis}

Results of this study were expressed as Mean \pm standard deviation (Mean $\pm \mathrm{SD}$ ). The significance of difference between the control and the other groups (G1A and $\mathrm{G} 1 \mathrm{~B}$, and G2A and G2B) was performed using one-way analysis of variance (ANOVA) for repeated measurements, with significance assessed at 5\% confidence level.

\section{Results and discussions}

\section{Rheological parameters measurement}

The relationship between shear stress and shear rate for 10 and $50 \mathrm{~nm}$ GNPs administered daily into rats for periods of 3 and 7 days at wide range of shear rates (from 225 to $1350 \mathrm{~s}^{-1)}$ and at fixed temperature of $37^{\circ} \mathrm{C}$ were measured (Figures 1, 2 and 3).

The relationship between shear stress and shear rate was linearly related. The linear flow rate relation for the 10 and $50 \mathrm{~nm}$ GNPs were described by the following equations:

\author{
Control: $\quad \mathrm{Y}=0.0148 \mathrm{X}+0.2101(\mathrm{R}=0.999)$ \\ $10 \mathrm{~nm}(\mathrm{G} 1 \mathrm{~A}): \quad \mathrm{Y}=0.0146 \mathrm{X}+0.0060(\mathrm{R}=1.000)$ \\ $10 \mathrm{~nm}(\mathrm{G} 1 \mathrm{~B}): \quad \mathrm{Y}=0.0159 \mathrm{X}-0.0138(\mathrm{R}=0.999)$ \\ $50 \mathrm{~nm}(\mathrm{G} 2 \mathrm{~A}): \quad \mathrm{Y}=0.0143 \mathrm{X}+0.1691(\mathrm{R}=0.999)$
}

$50 \mathrm{~nm}(\mathrm{G} 2 \mathrm{~B}): \quad \mathrm{Y}=0.0144 \mathrm{X}+0.0906(\mathrm{R}=0.999)$

The plastic viscosity (a measure of the internal resistance to fluid flow expressed as the tangential shear stress in excess of the yield stress divided by the resulting rate of shear)[17], yield stress (dyne $/ \mathrm{cm}^{2}$ ) (the minimum stress needed to cause the flow), consistency index (k) (an indication of the viscous nature of GNPs), the flow behaviour index (n) (a measure of departure from Newtonian flow) were calculated for different GNP sizes as shown in Additional File - Table 1.

\section{Rheological parameters measurement for blood plasma of rats with different sizes and periods of administration of GNPs (Additional File 1, Table 1)}

The plastic viscosity and yield stress parameters were calculated from fitting the experimental data for the different GNPs sizes. The plastic viscosity and the yield stress values for G1A, G1B, G2A and G2B significantly $(\mathrm{p}<0.05)$ decreased compared with the control.

The $\mathrm{n}$ and $\mathrm{k}$ values were calculated from equation (1). The $k$ values for G1A, G1B and G2B decreased compared with the control; however the means were not significantly different. While G2A indicates no significant change compared with the control. The values of the flow behaviour index $(\mathrm{n})$ were equal $\leq 1$ for all the different GNPs sizes.

The viscosity values measured for the different GNPs sizes at periods of 3 and 7 days and wide range of shear rate $\left(375-1875 \mathrm{~s}^{-1}\right)$ are shown in Additional File 1, Table 1. The viscosity values for 10 and $50 \mathrm{~nm}$ GNPs (G1A, G1B, G2A and G2B) decreased compared with the control; however the means were not significantly different. The decrease in blood plasma viscosity observed for all GNPs is particle size and administration period independent.

The data in the present study suggests that, at these particular shear rates, the estimated rheological parameters are not influenced by particles size, shape, number of NPs, surface area and administration period of GNPs.

This study suggests that the decrease in blood plasma viscosity induced with 10 and $50 \mathrm{~nm}$ GNPs may be attributed to decrease in hematocrit and cytoplasmic haemoglobin concentration of erythrocytes, and to the high erythrocyte deformability (the degree of shape 


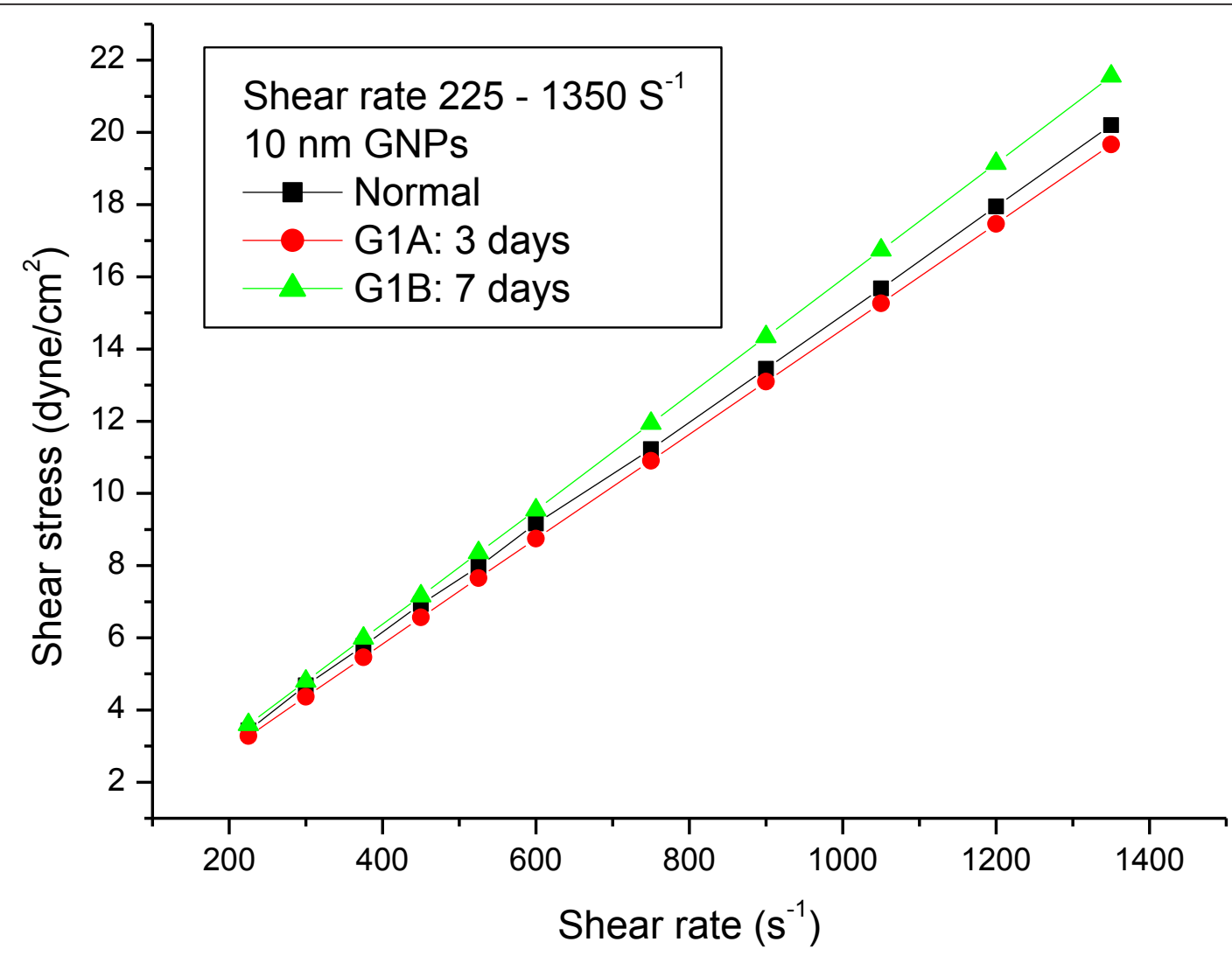

Figure 1 The relationship between shear stress and shear rate for blood plasma of rats with $10 \mathrm{~nm}$ gold nanoparticles at periods of 3 and 7 days (the means are not significantly different $(p<0.05)$ ).

change under a given level of applied shear stress and shear rate). The higher temperature or $\mathrm{pH}$ sensitivity of protein has higher plasma viscosity results. Inflammations, tissue injuries resulting in plasma protein changes can increase its value with high sensitivity, though low specificity $[6,7,17]$.

The factors that affect blood viscosity are plasma protein concentration and types of proteins in plasma, but these effects are so much less than the effect of hematocrit. The elevation of plasma viscosity correlates to the progression of coronary and peripheral vascular diseases. Anaemia can lead to decrease in blood viscosity, which may lead to heart failure [1-3].

The deformability is an intrinsic property of erythrocytes which can be determined by the geometric and material properties of this unique cell [6]. Erythrocytes change their shape extensively under the influence of applied shear stress in fluid flow or while passing through microcirculation. The extent and geometry of this shape change is determined by the rheological properties of erythrocytes, the magnitude of the applied forces and the orientation of erythrocytes with the applied forces.

The viscoelastic behaviour of erythrocytes is determined by the following three properties: 1) Geometry of erythrocytes; the biconcave-discoid shape provides an extra surface area for the cell, enabling shape change without increasing surface area. 2) Cytoplasmic viscosity; reflecting the cytoplasmic haemoglobin concentration of erythrocytes. 3) Visco-elastic properties of erythrocyte membrane, which can mainly be determined by the special membrane skeletal network of erythrocytes $[5,17]$.

The effect of protein on plasma viscosity depends on its molecular weight and structure. The less spheroid shape is the higher molecular weight and aggregating capacity. The higher temperature or $\mathrm{pH}$ sensitivity of protein has the higher plasma viscosity results [4,7].

Human blood plasma is a Newtonian fluid and its viscosity does not depend on flow characteristics, its control value is $1.10-1.30 \mathrm{mPas}$ at $37^{\circ} \mathrm{C}$, and it does not depend on the age and gender [6].

The GNPs strongly associate with the essential blood proteins where the binding constant as well as the degree of cooperativity of particle-protein binding, depends on particle size and the native protein structure. Moreover, the thickness of the adsorbed protein layer progressively increases with NP size, effects that have potential general importance for understanding NP 


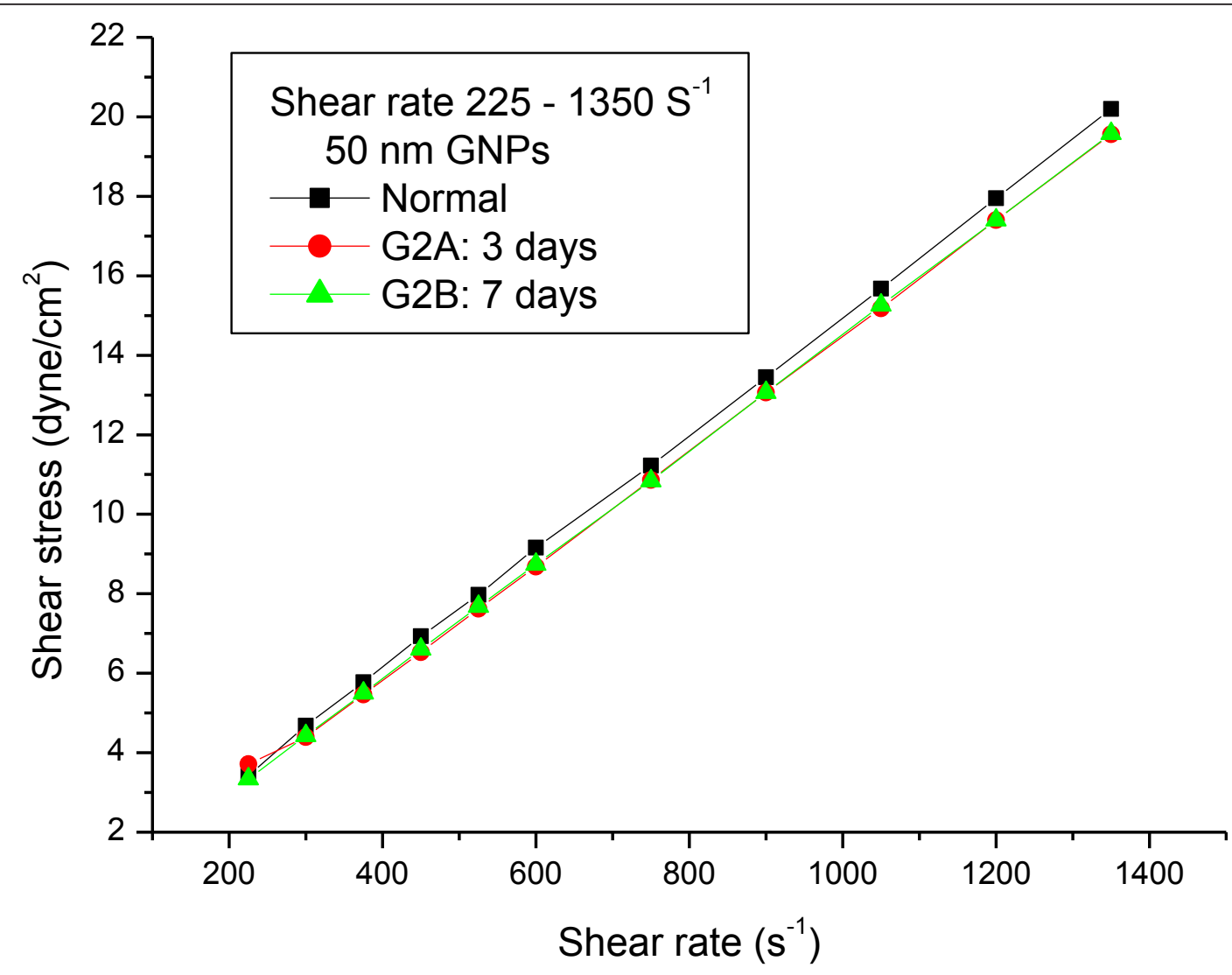

Figure 2 The relationship between shear stress and shear rate for blood plasma of rats with $\mathbf{5 0} \mathrm{nm}$ gold nanoparticles at periods of 3 and 7 days (the means are not significantly different $(p<0.05)$ ).

aggregation in biological media and the interaction of NP with biological materials $[9,11,18,19]$.

This study suggests that the administration of GNPs may induce appearance of hepatocytes cytoplasmic degeneration and nuclear destruction due to the interaction with proteins and enzymes of the hepatic tissue, which in turn interfering with the antioxidant defence mechanism and leading to reactive oxygen species (ROS) generation which induce stress in the hepatocytes to undergo atrophy and necrosis. Thus, to evaluate inflammations and tissue injuries, more histomorphologcal, histochemical and ultrastrucural investigations are needed in relation to the application of GNPs with their potential threat as a therapeutic and diagnostic tool.

\section{Conclusions}

This study is unique in evaluating various rheological parameters for blood plasma of rats after intraperitoneal administration of $100 \mu \mathrm{l}$ of 10 and $50 \mathrm{~nm}$ GNPs for periods of 3 and 7 days at fixed temperature of $37^{\circ} \mathrm{C}$ and wide range of shear rates using Brookfield LVDV-III Programmable rheometer.
The relationship between shear stress and shear rate observed with 10 and $50 \mathrm{~nm}$ GNPs confirmed with the power law behaviour.

The mean viscosity values measured for 10 and $50 \mathrm{~nm}$ GNPs (G1A, G1B, G2A and G2B) decreased compared with the control; however the means were not significantly different. The decrease in blood plasma viscosity values observed with all GNPs is particle size and administration period independent. The decrease in blood plasma viscosity may be attributed to decrease in hematocrit and cytoplasmic haemoglobin concentration of erythrocytes, and to the high erythrocyte deformability. The decrease in blood viscosity may lead to anaemia and/or heart failure.

The data in the present study demonstrates that, at these particular shear rates, the estimated rheological parameters are not influenced by particle size, shape, number of NPs, surface area and administration period of GNPs.

This study suggests that the intraperitoneal administration of GNPs may induce appearance of hepatocytes cytoplasmic degeneration and nuclear destruction due 


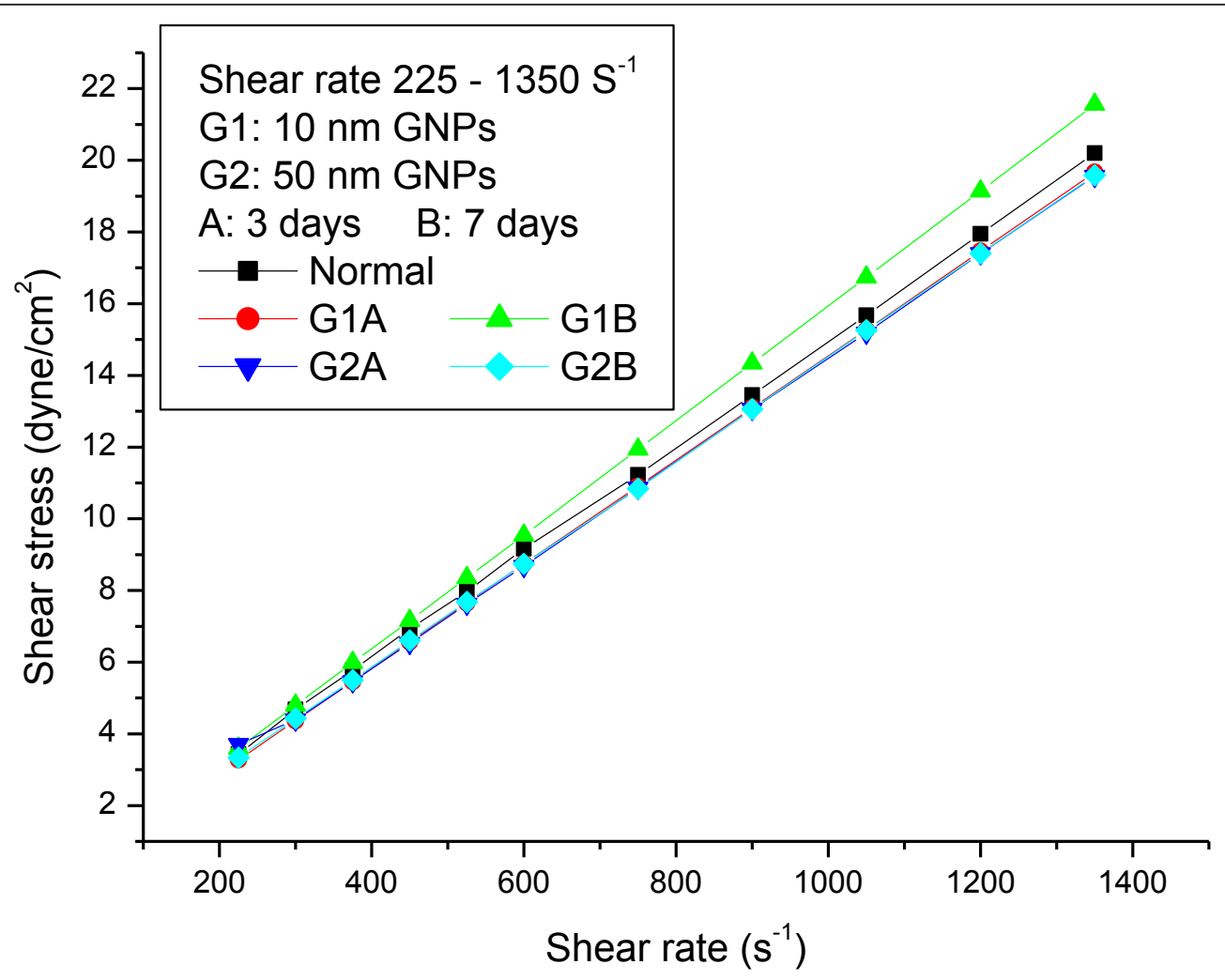

Figure 3 The relationship between shear stress and shear rate for blood plasma of rats with 10 and $50 \mathrm{~nm}$ gold nanoparticles at periods of 3 and 7 days (the means are not significantly different $(p<0.05)$ ).

to the interaction with proteins and enzymes of the hepatic tissue, which in turn interfering with the antioxidant defence mechanism and leading to reactive oxygen species (ROS) generation.

Thus, to evaluate inflammations and tissue injuries associated with GNPs, more histomorphologcal, histochemical and ultrastrucural investigations are needed in relation to the application of GNPs as a therapeutic and diagnostic tool.

\section{Additional material}

Additional file 1: Table 1. Rheological parameters measurement for blood plasma of rats with different sizes and periods of administration of GNPS.

\section{Acknowledgements}

The authors are very grateful to National Plan of Science and Technology (NPST). This research was financially supported by the National Science and Technology Innovation Plan (NSTIP), Research No. 08-ADV206-02 and Research No. 09-NAN670-02, College of Science, King Saud University, Saudi Arabia.

\section{Authors' contributions}

AMAK has analyzed data, interpreted and written the final draft of this manuscript. The animal model used in this study was obtained from the Laboratory Animal Center (College of Pharmacy, King Saud University). AMAK has conceived the plan and the design, and has obtained the research grant for this study. Moreover, the author has read and approved the final manuscript.

\section{Competing interests}

The author declares that he has no competing interests.

Received: 30 September 2011 Accepted: 27 October 2011

Published: 27 October 2011

\section{References}

1. Chien S: Red cell deformability and its relevance to blood flow. Annual Review of Physiology 1987, 49:177-192.

2. Baskurt OK, Hardeman M, Rampling MW, Meiselman HJ: Handbook of Hemorheology and Hemodynamics. Amsterdam, Netherlands, IOS Press; 2007.

3. Goldsmith $H L$, Turitto VT: Rheological aspects of thrombosis and haemostasis: Basic principles and applications. Thromb Haemost 1986, 55:415-35

4. Mohandas N, Chasis JA: Red blood cell deformability, membrane material properties and shape: regulation by transmembrane transmembrane, skeletal and cytosolic proteins and lipids. Seminars in Hematology 1993, 30(3):171-192.

5. Dutta A, Tarbell JM: Influence of non-Newtonian behavior of blood on flow in an elastic artery model. J Biomech Eng 1996, 118:111-119.

6. Késmárky $G$, Kenyeres $P$, Rábai M, Tóth K: Plasma viscosity: a forgotten variable. Clinical Hemorheology and Microcirculation 2005, 39:243-246.

7. Baskurt OK, Boynard M, Cokelet GC, et al: New guidelines for hemorheological laboratory techniques. Clinical Hemorheology and Microcirculation 2009, 42:75-97.

8. El-Sayed IH, Huang X, El-Sayed MA: Selective laser photo-thermal therapy of epithelial carcinoma using anti-EGFR antibody conjugated gold nanoparticles. Cancer Lett 2006, 239:129-135. 
9. Sperling RA, Gil PR, Zhang F, Zanella M, Parak WJ: Biological applications of gold nanoparticles. Chem Soc Rev 2008, 37:1896-1908.

10. Mirkin CA, Letsinger RL, Mucic RC, Storhoff JJ: A DNA based method for assembling nanoparticles. Nature 1996, 382:607-609.

11. Sandhu KK, McIntosh CM, Simard JM, Smith SW, Rotello VM: Gold nanoparticle-mediated transfection of mammalian cells. Bioconjug Chem 2002, 1:3-6.

12. Huber M, Wei TF, Muller UR, Lefebvre PA, Marla SS, Bao YP: Gold nanoparticle probe-based gene expression analysis with unamplified total human RNA. Nucleic Acids Res 2004, 32:e137-e145.

13. Tokonami S, Shiigi H, Nagaoka T: Preparation of Nanogapped Gold Nanoparticle Array for DNA Detection. Electroanalysis 2008, 20:355-360.

14. Tefferi A: A contemporary approach to the diagnosis and management of polycythemia vera. Hematol Rep 2003, 2(3):237-41.

15. Huang X, Jain PK, El-Sayed IH, El-Sayed MA: Special Focus: Nanoparticles for Cancer Diagnosis \& Therapeutics - Review; Gold nanoparticles: interesting optical properties and recent applications in cancer diagnostics and therapy. Nanomedicine 2007, 2:681-693.

16. Mady MM, Darwish M, Khalil S, Khalil W: Biophysical studies on chitosancoated liposomes. Eur Biophysics J 2009, 38:1127-1133.

17. Steffe J: Rheological methods in food process engineering. Mitchigan State University 1996, USA. 2 edition. Freeman Press;21.

18. Silvia H, Lacerda DP, Park JJ, Meuse C, Pristinski D, Becker ML, Karim A Douglas JF: Interaction of gold nanoparticles with common human blood proteins. ACS Nano 2010, 4:365-379.

19. Koenig W, Ernst E: The possible role of hemorheology in atherothrombogenesis. Atherosclerosis 1992, 94:93-107.

doi:10.1186/1476-511X-10-191

Cite this article as: Abdelhalim: The effects of size and period of administration of gold nanoparticles on rheological parameters of blood plasma of rats over a wide range of shear rates: In vivo. Lipids in Health and Disease 2011 10:191.

\section{Submit your next manuscript to BioMed Central} and take full advantage of:

- Convenient online submission

- Thorough peer review

- No space constraints or color figure charges

- Immediate publication on acceptance

- Inclusion in PubMed, CAS, Scopus and Google Scholar

- Research which is freely available for redistribution

Submit your manuscript at www.biomedcentral.com/submit
Biomed Central 